\title{
Viral Clearance Course of COVID-19 Outbreaks
}

This article was published in the following Dove Press journal:

Journal of Multidisciplinary Healthcare

\author{
Shaher M Samrah (D)' \\ Abdel-Hameed Al- \\ Mistarehi $\mathbb{D}^{2}$ \\ Tariq Kewan ${ }^{3}$ \\ Sohaib M Al-Khatib $\mathbb{D}^{4}$ \\ Ali M Ibnian (D) \\ Randa S Samrah ${ }^{5}$ \\ Basheer Y Khassawneh (D) \\ 'Department of Internal Medicine, \\ Faculty of Medicine, Jordan University of \\ Science and Technology, Irbid, Jordan; \\ ${ }^{2}$ Department of Public Health and Family \\ Medicine, Faculty of Medicine, Jordan \\ University of Science and Technology, \\ Irbid, Jordan; ${ }^{3}$ Department of Internal \\ Medicine, Cleveland Clinic, Cleveland, \\ $\mathrm{OH}$, USA; ${ }^{4}$ Department of Pathology and \\ Laboratory Medicine, Faculty of \\ Medicine, Jordan University of Science \\ and Technology, Irbid, Jordan; ${ }^{5}$ Faculty of \\ Medicine, Jordan University of Science \\ and Technology, Irbid, Jordan
}

Correspondence: Shaher M Samrah Faculty of Medicine, Jordan University of Science and Technology, P.O.Box: 63000I, Irbid, 22II0, Jordan

Email samrah@just.edu.jo

Abdel-Hameed Al-Mistarehi

Department of Public Health and Family Medicine, Faculty of Medicine, Jordan

University of Science and Technology,

P.O.Box: 63000I, Irbid, 22110, Jordan

Email awalmistarehil8@med.just.edu.jo
Background: Coronavirus disease 2019 (COVID-19) viral course and behavior remain unpredictable. This study describes incubation time and viral clearance of COVID-19 hospitalized cases in Northern Jordan.

Methods: All COVID-19 confirmed cases hospitalized from March 15 to June 09, 2020, were included. Nasopharyngeal swabs were collected, and COVID-19 reverse transcriptionpolymerase chain reaction (RT-PCR) was performed every two days in all cases. The viral cure was defined when two negative RT-PCR tests were obtained $\geq 24$ hours apart. Viral clearance time (VCT) reflects the time from the first positive nasopharyngeal swab to the first of two consecutive negative tests.

Results: In this cohort, a total of 157 patients were included. Most cases resulted from two major outbreaks. The median incubation period was 6 days (IQR, 3-10) and ranged from 1 to 17 days. The median VCT was 13 days (IQR, 7-2) and ranged from 1 to 40 days. Symptomatic presentation and abnormal chest radiograph were predictors for a prolonged $\operatorname{VCT}$ ( $p=0.015$ and $p=0.014$, respectively). The median time of resolution of symptoms was 7 days (IQR, 3-10 days). Most symptomatic cases (91.7\%) remained RT-PCR positive for up to 20 days after symptoms resolution, with a median of 13.5 days. VCT significantly correlated with the incubation period $(p=0.013)$.

Conclusion: Viral cure lagged for as long as 20 days after resolution of symptoms. Continuing with social-distancing, frequent hand hygiene, and wearing facial mask remains essential and is recommended even after clinical resolution of symptoms.

Keywords: viral clearance, viral shedding, incubation period, COVID-19, coronavirus, pandemic, CDC

\section{Introduction}

Learning the pattern and duration of coronavirus disease 2019 (COVID-19) viral clearance and recovery influencing factors is vital in understanding the disease pathogenesis, its natural course, and treatment effects for severe acute respiratory syndrome coronavirus 2 (SARS-CoV-2) infection. Such information is helpful in eliminating unnecessary testing and utilizing hospital resources. This will also help optimize laboratory and human resources and hospital beds utilization. Data regarding viral shedding, incubation period and possible predictors of negative conversion among COVID-19 patients are scarce, particularly in asymptomatic or mildly affected cases, which constitute the vast majority of COVID-19 presentation; as few studies conducted frequent testing and close monitoring to COVID-19 cases. ${ }^{1-4}$ Furthermore, asymptomatic and mild cases are usually quarantined without conducting sequential surveillance of virology profiles. During the early phase of fighting the COVID-19 pandemic in Jordan, the ministry of health initially launched a series of aggressive measures to contain the disease spread by isolating 
and forcing a mandatory quarantine of all laboratoryconfirmed COVID-19 cases, including asymptomatic ones, in designated hospitals. ${ }^{1,5,6}$ King Abdullah University Hospital (KAUH) was the designated hospital for the Northern Jordan region. The hospital serves a population exceeding 2 million. As part of a hospital adopted protocol, a serial of nasopharyngeal swabs were collected every two days in all cases, and real-time reverse transcriptase-polymerase chain reaction assay (RT-PCR) was conducted to detect viral negative-conversion (viral cure) as early as possible to facilitate early hospital discharge.

This study ascertained the incubation period and viral clearance among closely monitored asymptomatic and mildly affected COVID-19 patients and examined the effects of different clinical, laboratory, and radiological characteristics on the recovery rate.

\section{Materials and Methods}

\section{Participants, Study Design, Specimen, and} Data Collection

This single-center, retrospective cohort study was conducted at KAUH, Irbid, Jordan and included all hospitalized patients with laboratory-confirmed COVID-19 infection from March 15 to June 09, 2020. A confirmed case of COVID-19 was defined by a positive SARS-CoV-2 RT-PCR test in specimens collected by nasopharyngeal swabs. Patients were divided into non-prolonged and prolonged shedding groups according to nucleic acid conversion time ( $<14$ days vs $\geq 14$ days). ${ }^{7}$ Electronic medical records of all patients with laboratory-confirmed COVID19 infection were reviewed. Demographic, clinical, laboratory, radiological, treatment, and outcome data were extracted from electronic medical records. Data that was not available in the medical records were obtained through direct communication with patients or their families. Written informed consent was obtained from the recruited patients prior to study commencement, and this study was approved by the institutional review board (IRB) and the research and ethics committee at Jordan University of Science and Technology.

\section{Clinical Management}

According to the protocol adopted by the hospital in concordance with the national infectious disease committee recommendations at the time of the study, unless contraindicated, all adult symptomatic and asymptomatic patients who had confirmed COVID-19 by RT-PCR received a 10-day course of hydroxychloroquine (HCQ) regardless of the severity of their illness. HCQ was given $400 \mathrm{mg}$ twice daily on the first day, followed by $200 \mathrm{mg}$ twice daily for the following nine days. Additionally, appropriate empiric broad-spectrum antibiotics were administered to patients with suspected community-acquired pneumonia. Unless clinically contraindicated, all patients received a prophylactic dose of low molecular weight heparin and stress ulcer prophylaxis with a proton pump inhibitor during their hospital stay. Systemic corticosteroids were avoided unless clinically indicated.

\section{Specimen Collection and Testing and Definitive Variables}

Clinical Specimens for COVID-19 diagnostic testing were collected and analyzed according to the Centers for Disease Control and Prevention (CDC) guidelines. ${ }^{8}$ Nasopharyngeal swabs were collected by trained medical staff (physicians and nurses) and tested for SARS-CoV-2 detection. The first viral detection test was performed upon admission of the patient. After that, the nasopharyngeal swabs and viral detection tests were repeated every other day in the early morning before toothbrushing and breakfast until the patient had a negative test result. The initial negative test result was then confirmed the following day again. Patients were discharged home following "test-based" strategy suggested by the CDC at the time of conducting this study, which includes; resolution of fever without the use of fever-reducing medication, improvement in respiratory symptoms, and negative results of at least two consecutive nasopharyngeal swab specimens collected $\geq 24$ hours apart. ${ }^{9}$ The period from the date of the first positive result to the date of the first two consecutive negative RT-PCR test results was defined as a viral cure/viral clearance time (VCT). The incubation period was estimated as the days elapsed between the dates of travel or contact exposure and the onset of symptoms for the symptomatic patients. ${ }^{10}$

\section{SARS-CoV-2 Detection Test}

SARS-CoV-2 detection in nasopharyngeal specimens was conducted by SARS-CoV-2 Nucleic Acid Detection Kit (PCR-Fluorescent Probe Method) manufactured by Zybio Inc. with a product code of 1.10.11.09.nc.02. This kit qualitatively detects the RNA of SARS-CoV-2 in the specimen through a one-step real-time RT-PCR method 
targeting Open Reading Frame 1ab (ORF1ab), and Nucleocapsid protein (N) genes. Specimens were collected in the biosafety cabinet of the BSL-2 laboratory after sampling and stored in freezing-resistant tubes. Specimens were tested immediately or stored at 2-8 C for no more than 24 hours or $-20 \pm 5 \mathrm{C}$ for no more than three months. RNA was extracted from the samples and then underwent real-time RT-PCR with SARS-CoV -2-specific primers and probes designed according to the conserved sequences of ORF1ab and N genes. Qualitative detection of SARS-CoV-2 was released by monitoring the change of fluorescence signal intensity during RT-PCR amplification. Cycle threshold $(\mathrm{Ct})$ values and amplification curves of FAM ( $\mathrm{N}$ gene) and ROX (ORF1ab result) fluorescence channels were used to approximately reflect the viral loads (inversely related to Ct-values) in the respiratory tract. The typical S-shaped amplification curves of FAM and ROX fluorescence channels and $\mathrm{Ct}$ values below 40 was defined as a positive test, while not detected FAM and ROX fluorescence channels or $\mathrm{Ct}$ values of 45 or more with VIC channel $\mathrm{Ct}<40$ was considered as a negative test. A gray zone result required confirmation by re-testing, defined as $\mathrm{Ct}$ values between 40 and 45, and VIC channel $\mathrm{Ct}<40$. If the repeated test showed the same results, but with typical S-shaped curves, the result was deemed positive. Ct values of 45 or no value in FAM and ROX fluorescence channels, and $\mathrm{Ct} \geq 40$ or no value in VIC channel indicating that the result was invalid, and a re-test was needed.

\section{Statistical Analysis}

The IBM Statistical Package for Social Sciences Software (SPSS) for Windows, version 25.0, was used for data processing and analysis. Patients' characteristics were described using frequencies and percentages for categorical variables. Continuous variables were presented as medians with interquartile ranges (IQRs) as they were not normally distributed. Bivariate correlation using the Pearson correlation coefficient (r) was conducted to test the relationships between two-time pertinent findings of COVID-19 patients. Using the measured median VCT in our study of 13 days, univariate and multivariate analyses were performed to detect the predictors of prolonged VCT as defined by a duration of equal or more than 14 days. A chi-square test or Fisher's exact test was used to assess the categorical variables, whereas continuous variables were analyzed by the nonparametric Mann-Whitney $U$-test and Kaplan-Meier test. After that, a binary logistic regression analysis test was conducted with adjusting for the significant factors selected by univariate analysis to tease out the independent predictors for prolonged VCT. Odds ratio (OR) and their 95\% confidence intervals (95\% CI) were reported. A $p$-value of less than 0.05 was considered statistically significant.

\section{Results}

A total of 158 COVID-19 patients were admitted to KAUH during the study period as a result of two main outbreaks in the Northern Jordan region. With one mortality out of 158 admitted cases, a total of 157 COVID-19 patients were included in this study. The median (Interquartile Range, IQR) age was 30.0 (20-47) and ranged from 3 to 79 . More than half of the patients (57.3\%) were females. Tables 1 and 2 describe the demographic, clinical, laboratory, and radiological characteristics of the study cohort at the time of admission. About half of our patients $(46.5 \%)$ were asymptomatic. In the symptomatic group, the most common presenting symptoms were Upper Respiratory Tract infection symptoms (URTs), manifested as sore throat or/and nasal congestion, followed by cough, fatigue, and headache. The least common presenting symptoms were chest tightness and diarrhea.

The first outbreak occurred after an indoor 2-hour wedding party on March 13, 2020, resulting in a total of 76 admitted COVID-19 infected cases out of about 360 attendees. The presumed index case was the bride's father. ${ }^{11}$ The second major outbreak started on May 7 , 2020 , as a result of a large family launch gathering with a common exposure to an index case, a truck driver who crossed land borders from a neighboring country. This outbreak resulted in a total of 62 COVID-19 cases. In between these two outbreaks, two minor outbreaks took place and resulted in a total of 20 confirmed COVID-19 cases after exposure to recent travelers from endemic areas, which occurred despite the strict measures applied by the government towards incoming travelers from outside Jordan, which included mandatory home quarantine for up to 14 days to travelers coming from countries with a high incidence of new COVID-19 cases. ${ }^{6}$ The number of COVID-19 hospitalized patients from the first major outbreak increased gradually from March 16, 2020, and peaked with a total of 81 patients on April 2, 2020 (18 days after the starting of the outbreak). While it took 10 days to discharge the first admitted case of this outbreak, it took nearly 28 days from the peak to discharge the last case of this outbreak on April 30, 2020. The second 
Table I Demographics and Clinical Characteristics of COVID-19 Patients at the Time of Admission

\begin{tabular}{|c|c|c|c|c|}
\hline & \multirow[t]{2}{*}{ All Patients $(n=157)$} & \multicolumn{2}{|c|}{ Negative Conversion Rate (VCT) } & \multirow[t]{2}{*}{$p$-value* } \\
\hline & & < I4 Days $(n=89)$ & $\geq$ I4 Days $(n=68)$ & \\
\hline Age (years), median (IQR) & $30.0(20-47)$ & $30.0(23.5-46.5)$ & $27.0(19.0-47.8)$ & 0.893 \\
\hline Female gender & $90(57.3 \%)$ & $45(50.6 \%)$ & $45(66.2 \%)$ & 0.050 \\
\hline $\begin{array}{l}\text { BMI }\left(\mathrm{Kg} / \mathrm{m}^{2}\right), \text { median }(\mathrm{IQR})(\mathrm{n}=\mathrm{I} 2) \\
\quad \text { Obesity }\left(\geq 30 \mathrm{Kg} / \mathrm{m}^{2}\right)\end{array}$ & $\begin{array}{l}25.6(22.9-29.1) \\
29(22 \%)\end{array}$ & $\begin{array}{l}25.3(23.2-29.0) \\
16(21.1 \%)\end{array}$ & $\begin{array}{l}26.0(22.7-29.2) \\
13(23.2 \%)\end{array}$ & $\begin{array}{l}0.597 \\
0.767\end{array}$ \\
\hline $\begin{array}{l}\text { Cigarette smoking } \\
\text { Non-smoker } \\
\text { Current smoker }\end{array}$ & $\begin{array}{l}\text { I25 (79.6\%) } \\
32(20.4 \%)\end{array}$ & $\begin{array}{l}69(77.5 \%) \\
20(22.5 \%)\end{array}$ & $\begin{array}{l}56(82.4 \%) \\
12(17.6 \%)\end{array}$ & 0.457 \\
\hline $\begin{array}{l}\text { Any Comorbidity } \\
\text { HTN } \\
\text { DM } \\
\text { Dyslipidemia } \\
\text { IHD } \\
\text { Pregnant females }\end{array}$ & $\begin{array}{l}33(21 \%) \\
20(12.7 \%) \\
11(7 \%) \\
8(5.1 \%) \\
5(3.2 \%) \\
6(6.7 \%)\end{array}$ & $\begin{array}{l}22(24.7 \%) \\
12(13.5 \%) \\
7(7.9 \%) \\
5(5.6 \%) \\
4(4.5 \%) \\
3(6.7 \%)\end{array}$ & $\begin{array}{l}\text { II }(16.2 \%) \\
8(11.8 \%) \\
4(5.9 \%) \\
3(4.4 \%) \\
\text { I (I.5\%) } \\
3(6.7 \%)\end{array}$ & $\begin{array}{l}0.193 \\
0.749 \\
0.630 \\
0.733 \\
0.285 \\
1.000\end{array}$ \\
\hline Symptomatic & $84(53.5 \%)$ & $33(37.1 \%)$ & $51(75 \%)$ & $<0.001$ \\
\hline $\begin{array}{l}\text { Presenting symptoms } \\
\text { URTs } \\
\text { Cough } \\
\text { SOB } \\
\text { Chest tightness } \\
\text { Fever } \\
\text { Chills } \\
\text { Fatigue } \\
\text { Diarrhea } \\
\text { Headache }\end{array}$ & $\begin{array}{l}62(39.5 \%) \\
56(35.7 \%) \\
13(8.3 \%) \\
12(7.6 \%) \\
13(8.3 \%) \\
20(12.7 \%) \\
25(15.9 \%) \\
8(5.1 \%) \\
25(15.9 \%)\end{array}$ & $\begin{array}{l}24(27 \%) \\
24(27 \%) \\
4(4.5 \%) \\
5(5.6 \%) \\
5(5.6 \%) \\
7(7.9 \%) \\
13(14.6 \%) \\
4(4.5 \%) \\
11(12.4 \%)\end{array}$ & $\begin{array}{l}38(55.9 \%) \\
32(47.1 \%) \\
9(13.2 \%) \\
7(10.3 \%) \\
8(11.8 \%) \\
13(19.1 \%) \\
12(17.6 \%) \\
4(5.9 \%) \\
14(20.6 \%)\end{array}$ & $\begin{array}{l}<0.001 \\
\mathbf{0 . 0 0 9} \\
\mathbf{0 . 0 4 9} \\
0.275 \\
0.166 \\
\mathbf{0 . 0 3 6} \\
0.606 \\
0.695 \\
0.163\end{array}$ \\
\hline Developing new symptoms during admission & $26(16.6 \%)$ & $15(16.9 \%)$ & II (I6.2\%) & 0.910 \\
\hline $\begin{array}{l}\text { Vital signs, median }(\mathrm{IQR}) \\
\text { Temperature }\left({ }^{\circ} \mathrm{C}\right) \\
\text { Pulse oximeter O2 saturation \% } \\
\mathrm{SpO} 2 \leq 94 \% \\
\mathrm{HR} / \mathrm{min} \\
\mathrm{RR} / \mathrm{min} \\
\text { Systolic } \mathrm{BP}(\mathrm{mmHg}) \\
\text { Diastolic BP }(\mathrm{mmHg})\end{array}$ & $\begin{array}{l}37.0(36.8-37.2) \\
96.0(95.0-97.0) \\
16(10.2 \%) \\
87(80-98) \\
20(18-20) \\
120(110.8-130) \\
74.0(69.0-80.0)\end{array}$ & $\begin{array}{l}37.0(36.8-37.4) \\
96.0(95.0-97.0) \\
12(13.5 \%) \\
89.0(80.0-99.0) \\
20(18-20) \\
120(110-130) \\
75.5(69.0-80.8)\end{array}$ & $\begin{array}{l}36.9(36.7-37.1) \\
96.0(95.0-97.0) \\
4(5.9 \%) \\
85.0(80.0-96.5) \\
20(18-20) \\
118(112-130) \\
73.0(68.8-80.0)\end{array}$ & $\begin{array}{l}0.526 \\
0.865 \\
0.119 \\
0.118 \\
0.840 \\
0.498 \\
0.389\end{array}$ \\
\hline
\end{tabular}

Note: *A p-value of less than 0.05 was considered statistically significant as indicated in bold.

Abbreviations: BMI, body mass index; HTN, hypertension; DM, diabetes mellitus; IHD, ischemic heart disease; URTs, upper respiratory tract infection symptoms manifested by sore throat, or/and nasal congestion; SOB, shortness of breath; SpO2, pulse oximeter oxygen saturation.

major outbreak started on May 7, 2020, with a peak of 54 patients on May 15, 2020, nine days after the occurrence of the outbreak. Similar to the first outbreak, it took as long as 26 days from the date of the peak to discharge the last case of this outbreak (June 9, 2020). Figure 1 shows the chronicle of the number of hospitalized and discharged COVID-19 patients as a result of these outbreaks.
Table 3 summarizes the time kinetics of viral clearance, hospital stay, symptoms onset, and resolution. Our study's measured median VCT was 13 days (IQR, 7-2) and ranged from as short as one day to as long as 40 days. The median incubation period from estimated exposure to onset of symptoms was 6 days (IQR of 3-10) and ranged from 1 day up to 17 days. Interestingly, four out of the 84 (4.8\%) symptomatic patients had an incubation period 
Table 2 Laboratory and Radiographic Findings on the Day of Admission to the Hospital and Hydroxychloroquine Treatment

\begin{tabular}{|c|c|c|c|c|}
\hline & \multirow[t]{2}{*}{ All Patients $(n=157)$} & \multicolumn{2}{|c|}{ Negative Conversion Rate } & \multirow[t]{2}{*}{ p-value* } \\
\hline & & < I4 Days $(n=89)$ & $\geq 14$ Days $(n=68)$ & \\
\hline \multicolumn{5}{|l|}{ Laboratory findings } \\
\hline $\mathrm{WBC} \times 10^{3} / \mathrm{mm}^{3}$, median & 6.60 & 7.10 & 6.40 & 0.155 \\
\hline $\mathrm{WBC}<4 \times 10^{3} / \mathrm{mm}^{3}$ & $19(12.1 \%)$ & $10(11.2 \%)$ & $9(13.2 \%)$ & 0.703 \\
\hline$W B C>11 \times 10^{3} / \mathrm{mm}^{3}$ & $10(6.4 \%)$ & $6(6.7 \%)$ & $4(5.9 \%)$ & 0.827 \\
\hline Neutrophils $\times 10^{3} / \mathrm{mm}^{3}$, median & 3.63 & 4.14 & 3.38 & 0.043 \\
\hline Neutrophils $<1500 / \mathrm{mm}^{3}$ & $8(5.1 \%)$ & $4(4.5 \%)$ & $4(5.9 \%)$ & 0.695 \\
\hline Neutrophils $>7000 / \mathrm{mm}^{3}$ & $15(9.6 \%)$ & $14(15.7 \%)$ & $4(5.9 \%)$ & 0.047 \\
\hline Lymphocytes $\times 10^{3} / \mathrm{mm}^{3}$, median & 1.98 & 2.05 & 1.82 & 0.168 \\
\hline Lymphocytes $<1000 / \mathrm{mm}^{3}$ & $8(5.1 \%)$ & 7 (7.9\%) & I (I.5\%) & 0.071 \\
\hline Lymphocytes $>3000 / \mathrm{mm}^{3}$ & $28(I 7.8 \%)$ & 17 (19.1\%) & II (I6.2\%) & 0.635 \\
\hline Hemoglobin g/dl, median & 13.70 & 13.80 & 13.45 & 0.358 \\
\hline Low $\mathrm{Hb}<\mid 3 g / d l$ & $55(35 \%)$ & $28(31.5 \%)$ & 27 (39.7\%) & 0.283 \\
\hline Platelets $\times 10^{3} / \mathrm{mm}^{3}$, median & 213.00 & 218.00 & 210.50 & 0.551 \\
\hline Serum creatinine $\mu \mathrm{mol} / \mathrm{l}$, median & 62.00 & 62.00 & 58.50 & 0.807 \\
\hline ALT u/l, median & 15.20 & 16.50 & 15.00 & 0.872 \\
\hline AST u/l, median & 20.00 & 20.00 & 20.10 & 0.904 \\
\hline Serum albumin $\mathrm{g} / \mathrm{l}$, median & 46.00 & 46.00 & 46.25 & 0.794 \\
\hline CRP mg/l, median $(n=148)$ & 2.45 & 1.85 & 2.93 & 0.021 \\
\hline High CRP (>4 mg/l) & $53(35.8 \%)$ & $23(28.4 \%)$ & 30 (44.8\%) & 0.039 \\
\hline ESR mm/h, median $(n=142)$ & 15.00 & 15.00 & 16.00 & 0.623 \\
\hline High ESR (>20 mm/h) & 55 (38.7\%) & $29(37.7 \%)$ & $26(40 \%)$ & 0.776 \\
\hline D-dimer $\mu \mathrm{g} / \mathrm{mL}$, median $(n=146)$ & 0.98 & 1.00 & 0.95 & 0.867 \\
\hline Positive D-dimer ( $\geq \mathrm{I} \mu \mathrm{g} / \mathrm{mL})$ & $72(49.3 \%)$ & $43(51.2 \%)$ & $29(46.8 \%)$ & 0.598 \\
\hline LDH U/L, median $(n=122)$ & 434.00 & 437.00 & 431.00 & 1.000 \\
\hline High LDH (> 280 U/L) & 117 (95.9\%) & 75 (97.4\%) & $42(93.3 \%)$ & 0.274 \\
\hline \multicolumn{5}{|l|}{ Radiological findings $(n=122)$} \\
\hline Abnormal chest radiograph & $38 / 122$ (31.1\%) & $12 / 70(17.1 \%)$ & $26 / 52(50 \%)$ & $<0.001$ \\
\hline Unilateral patchy infiltrates & $15(39.5 \%)$ & 7 (58.3\%) & $8(30.8 \%)$ & 0.106 \\
\hline Bilateral patchy infiltrates & $23(60.5 \%)$ & $5(41.7 \%)$ & $18(69.2 \%)$ & \\
\hline \multicolumn{4}{|l|}{ Treatment (hydroxychloroquine) } & 0.749 \\
\hline Yes & I 37 (87.3\%) & 77 (86.5\%) & $60(88.2 \%)$ & \\
\hline No & $20(12.7 \%)$ & $12(13.5 \%)$ & 8 (II.8\%) & \\
\hline
\end{tabular}

Note: *A p-value of less than 0.05 was considered statistically significant as indicated in bold.

Abbreviations: WBC, white blood cells count; Hb, hemoglobin; ALT, alanine aminotransferase; AST, aspartate aminotransferase; CRP, C-reactive protein; ESR, erythrocyte sedimentation rate; $\mathrm{LDH}$, lactate dehydrogenase.

longer than 14 days. The median duration from onset to the resolution of symptoms was 7 days (IQR, 3-10 days). Most symptomatic cases $(77 / 84,91.7 \%)$ remained RTPCR positive for up to 20 days after resolving symptoms, with a median of 13.5 days. VCT correlated with the incubation period (Pearson Correlation $(r)=-0.284$, $p=0.013$ ). Shorter lapse-time from the time of estimated exposure to positive RT-PCR was associated with longer VCT. On the other hand, there was no correlation between VCT and duration from onset of symptoms to hospital admission or the resolution of symptoms $(p>0.05)$. More than half of COVID-19 patients from these outbreaks (56.7\%) achieved viral cure within the first two weeks of admission, but noticeably $7 \%$ of the patients remained RT- 


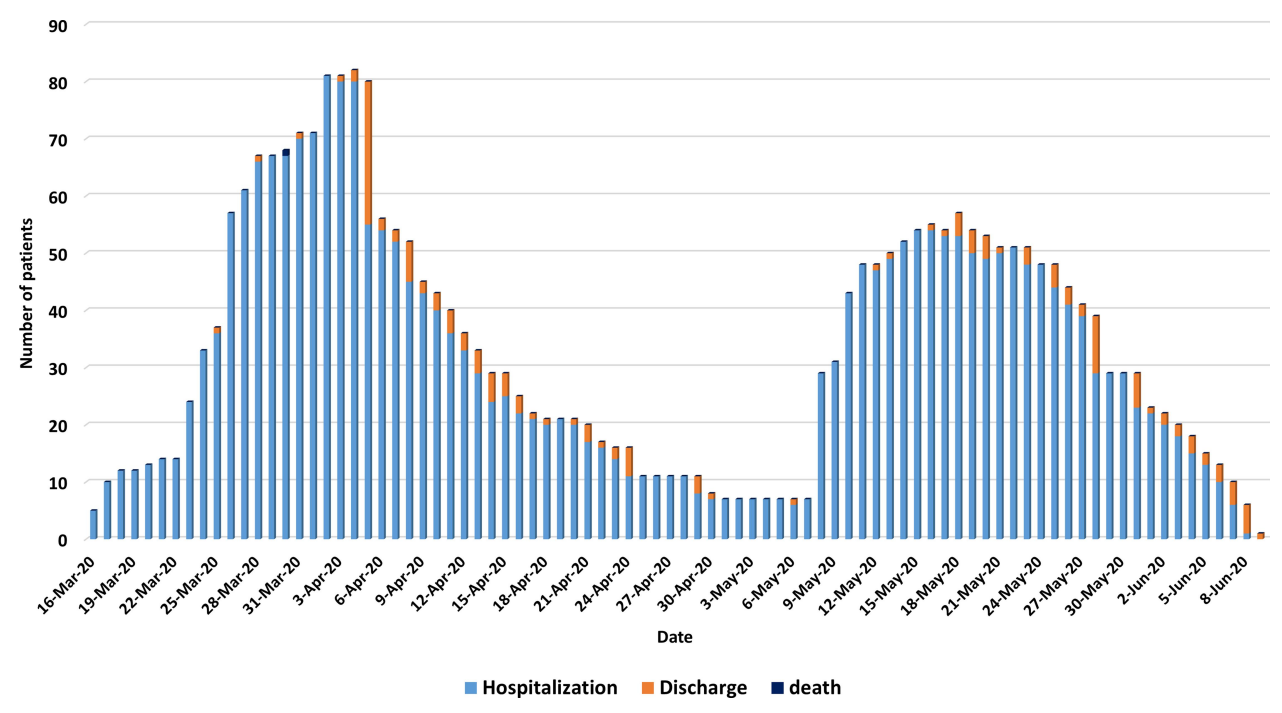

Figure I Daily number of patients' hospitalization, discharge, and death.

PCR positive four weeks after their first positive test (Figure 2).

Using the measured median VCT in our study of 13 days, the study sample was divided into two groups, nonprolonged (less than 14 days) and prolonged (14 days or more), in order to investigate the effect of multiple variables on $\mathrm{VCT}^{7}$ The majority of patients $(75 \%)$ who had prolonged VCT had COVID-19 symptoms upon admission. The presence of symptoms upon admission was the most noticeable difference between the two groups $(p<0.001)$. The median VCT among the symptomatic group was 16.5 days, compared to 7.0 days among the

Table 3 Two-Time Pertinent Findings of COVID-19 Patients

\begin{tabular}{|l|c|}
\hline & $\begin{array}{c}\text { Days Median } \\
\text { (IQR) }\end{array}$ \\
\hline VCT (first positive to first negative RT-PCR test) & $13(7-21)$ \\
\hline IP (Time of exposure to symptoms onset) & $6(3-10)$ \\
\hline CCT (symptoms onset to symptoms resolution) & $7(3-10)$ \\
\hline Time from symptoms onset to viral clearance & $22(14-28)$ \\
\hline Time from Clinical Cure to Viral Cure & $13.5(8-20)$ \\
\hline $\begin{array}{l}\text { Time from symptoms onset to hospital admission/ } \\
\text { virus positivity }\end{array}$ & $3(2-5)$ \\
\hline $\begin{array}{l}\text { Time from hospital admission to symptoms } \\
\text { resolution }\end{array}$ & $3(1-6)$ \\
\hline Duration of hospitalization & $16($ I0-23) \\
\hline
\end{tabular}

Abbreviations: VCT, viral clearance time; IP, incubation period; CCT, clinical cure time; IQR, interquartile range. asymptomatic group $(p<0.001)$ (Figure 3$)$. Among the symptoms, patients who presented with URTs had a prolonged VCT of 16 days, in comparison to 10 days without URTs ( $p=0.002$ ), and VCT was longer among patients who presented with cough (16 days vs 10 days, $p=0.013$ ); dyspnea ( 16 days vs 12 days, $p=0.045$ ); or chills (12 days vs 21 days, $p=0.044$ ). On the other hand, there was no difference in VCT between patients who had a fever, fatigue, chest tightness, diarrhea, or headache and patients without these symptoms $(p>0.05)$. Although not statistically significant, more COVID-19 patients with prolonged VCT were females $(66.2 \%, p=0.050)$. There was no difference between the two groups in regards to age, obesity, cigarette smoking, comorbidities, or presenting vital signs or oxygenation.

With the exception of a lower neutrophil count, and elevated C-Reactive Protein (CRP) in the prolonged group ( $p=0.043$ and $p=0.021$, respectively), there were no differences in the laboratory findings at the time of admission between the two groups. On the other hand, $50 \%$ of the COVID-19 patients in the prolonged group had an abnormal X-ray compared to the non-prolonged group (17\%) $(p<0.001)$ (Table 2$)$. The median VCT was prolonged of 17.5 days in COVID-19 patients with abnormal radiological findings, compared to 10 days in patients with normal chest X-rays at the time of presentation $(p=0.001)$ (Figure 4). Of all 157 COVID-19 cases included in the study, 20 (12.7\%) patients did not receive HCQ. There was no difference in VCT between patients who received HCQ treatment (13 days) and those who did not receive HCQ (11.5 days) $(p=0.923)$. 


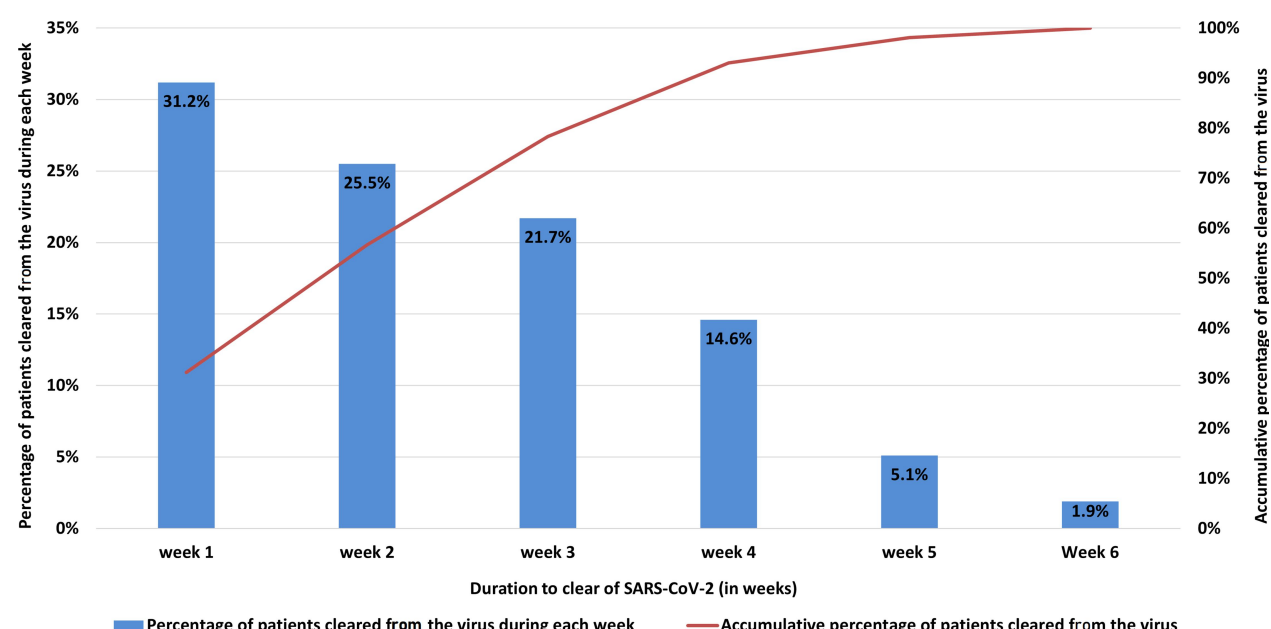

Figure 2 Duration to viral clearance in weeks.

Using binary logistic regression to detect the independent predictors of prolonged VCT while adjusting for confounding factors including gender, presence of symptoms at admission, neutrophilia, CRP, and chest radiograph findings. Symptomatic presentation upon admission and abnormal chest radiograph were independently associated with prolonged VCT beyond 14 days with an adjusted odds ratio (OR) of 3.03 (95\% CI 1.25-7.37, $p=0.015$ ) and an adjusted OR of 3.05 (95\% CI $1.25-7.45$, $p=0.014$ ), respectively, (Table 4).

\section{Discussion}

This study explains different aspects of the SARS CoV-2 infection course, from incubation time to viral clearance and correlation with host-related aspects. It describes various time frames of the natural clinical course of closely monitored laboratory-confirmed COVID-19 patients, up until clinical and viral cure. The study followed two main outbreaks in Northern Jordan and revealed that it took about four weeks from the time of each outbreak's peak to the time of hospital discharge of all affected patients. Such a prolonged hospital-stay length had certainly placed a burden on the health care system from relatively mild outbreaks. Although most symptomatic patients had symptoms resolution after an average of 7 days from onset of symptoms, most of the symptomatic cases $(91.7 \%)$ continued to have positive nasopharyngeal RT-PCR tests after symptoms resolution, with a median VCT of 13.5 days. Symptomatic COVID-19 patients or/ and those with abnormal chest $\mathrm{x}$-ray had prolonged viral clearance beyond 14 days, regardless of their age, gender, or presence of comorbidities.

The incubation period is epidemiologically critical during the COVID-19 pandemic as there is some evidence that asymptomatic and presymptomatic COVID-19 cases can spread the virus to close contacts. ${ }^{12-15}$ COVID-19

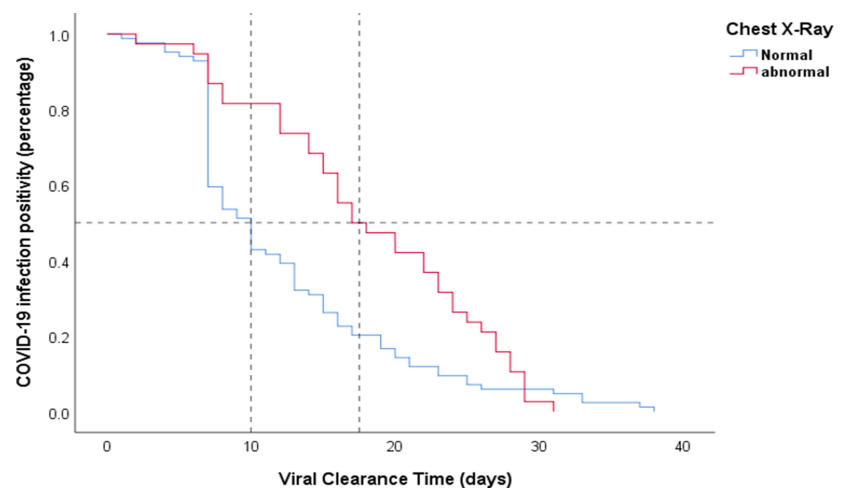

Figure 4 Kaplan-Meier curves for negative viral conversion ratio in COVID-19 patients according to radiological findings upon admission.

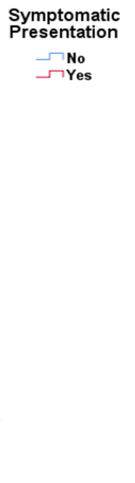


Table 4 Predictors of Prolonged Viral Clearance ( $\geq 14$ Days)

\begin{tabular}{|l|l|l|}
\hline Variable & Odds Ratio (95\% CI) & p-value* \\
\hline Female gender & $1.103(0.469-2.592)$ & 0.823 \\
\hline Symptomatic presentation & $3.030(1.245-7.373)$ & $\mathbf{0 . 0 1 5}$ \\
\hline Neutrophils $>7000 / \mathrm{mm} 3$ & $0.408(0.108-1.550)$ & 0.188 \\
\hline High CRP $(>4 \mathrm{mg} / \mathrm{l})$ & $1.256(0.535-2.949)$ & 0.601 \\
\hline Abnormal chest radiograph & $3.053(1.25 \mathrm{I}-7.450)$ & $\mathbf{0 . 0 1 4}$ \\
\hline
\end{tabular}

Note: *A p-value of less than 0.05 was considered statistically significant as indicated in bold.

Abbreviations: CRP, C-reactive protein; $\mathrm{Cl}$, confidence interval.

generally had a longer incubation period than SARS and Middle East Respiratory Syndrome. ${ }^{16}$ The median (IQR) incubation period found in our study was 6 (3-10) days, but it extended to as long as 17 days in some cases. The first estimation of the COVID-19 infection incubation period was conducted by a study from Wuhan, which reported a mean incubation period of 5.2 days with the 95th percentile of the distribution at 12.5 days. ${ }^{17}$ Later studies described a mean incubation period of 5-6.5 days. ${ }^{18,19}$ However, a recent study on 2907 cases in China found that the incubation period may be prolonged to 24.0 days. $^{20} \mathrm{~A}$ case with an incubation period of 19 days was observed in a previous study of 5 cases. $^{21}$

Multiple factors were described to play a role in predicting the disease's course and prognosis, including male sex, obesity, presence of comorbidities, high levels of D-dimer, low albumin, high CRP and ferritin levels, and presence of hypoxemia at the time of presentation. ${ }^{22-26}$ The median VCT in our cohort was 13 days and was prolonged in symptomatic patients. Young et al reported a median viral shedding of 12 days, with a majority of patients $(83 \%)$ had viral shedding from the nasopharynx detected for seven days or longer. ${ }^{27}$ Another study was conducted on 193 symptomatic and 110 asymptomatic patients and found that the median duration of viral shedding was shorter in asymptomatic patients. ${ }^{28} \mathrm{~A}$ recent study on a total of 396 non-severe COVID-19 patients found that the VCT was significantly shorter in the asymptomatic group with a median (IQR) of 14.5 days (11.0-21.0) than in the symptomatic group with a median (IQR) of 18.0 days $(15.0-22.0), \quad(p=0.001) .{ }^{29}$ Another study found that unlike severe cases that remained test-positive after ten days, most of the mild cases had a viral cure by day-ten from the onset of symptoms. ${ }^{30}$ Data coming from china usually include younger populations in comparison to the European studies. Most European cohorts were found to have a slower recovery with more prolonged viral shedding. ${ }^{31,32}$ Bongiovanni et al reported a mean time for viral clearance of 31.8 days in a total of 142 healthcare workers, with a maximum of 55 days and prolonged in symptomatic cases compared to asymptomatic ( 34.2 versus 22 days, $p<0.0001$ ); however, no statistical correlation was observed for gender, age or severity of the disease. ${ }^{31}$

Most symptomatic COVID-19 patients in our study continued to have viral positivity after the resolution of symptoms for up to 20 days, with a median of 13.5 days. Chang et al reported a median viral shedding of 5.5 days, with up to half of the patients remained virus-positive for up to 8 days after resolving symptoms. ${ }^{33}$ However, in another study of 56 patients with mild to moderate illness, viral RNA shedding from pharyngeal specimens lasted for as long as 42 days after the onset of symptoms with a reported median duration of 24 days, and patients with prolonged viral shedding of more than 24 days tend to be older and more likely to have comorbidities such as diabetes mellitus, and hypertension. ${ }^{34}$ Bongiovanni et al collected data from 1146 patients with COVID-19 infection and followed them after hospital discharge with periodic nasopharyngeal swabs and reported a mean time for viral shedding of 27.7 days. $^{35}$ Interestingly, 125 patients $(10.9 \%)$ were tested positive 19.9 days after testednegative, raising the possibility of false-negative results due to technical errors in sampling the specimens or the sensitivity/specificity of the test kit versus intermittent shedding of RNA fragments or a true recurrence of COVID-19 infection. ${ }^{35}$

Liao et al indicated that advanced age, having severe chronic diseases, and severe illness were independent risk factors for higher viral RNA shedding. Patients with severe disease symptoms had prolonged viral shedding compared to those with mild symptoms $(p=0.01){ }^{36}$ Recent studies found that male sex, APACH II score, disease severity, lymphopenia, diarrhea, and delayed hospital admission after illness onset were all associated with prolonged SARS-CoV-2 RNA clearance time. ${ }^{37-39}$ Shi et al reported a median time of persistent viral shedding of 16 days, with a small subset of patients who had detectable levels of the virus up to 30 days from symptoms onset. ${ }^{37} \mathrm{~A}$ smaller retrospective study by Fang et al also found that the time of viral shedding was longer in patients admitted to ICU (15.67+6.68 days) compared to others $(22.25+3.62$ days $)(p=0.02){ }^{40}$ The authors suggested that 
higher viral load might be related to the disease's severity and, consequently, to a prolonged viral shedding to recovery. ${ }^{40}$ The largest study from Europe to date was done by Bongiovanni et al included 681 patients with COVID-19 infection diagnosed by a nasopharyngeal swab. ${ }^{32}$ Patients were categorized into three groups according to the time needed to "swab negativization", included: "Early-negativization" group ( $<3$ weeks) composed of 284 patients, "medium-negativization" group (3-6 weeks) composed of 225 patients, and "latenegativization" group ( $>6$ weeks) consisted of 172 patients. Although male sex was significantly associated with a prolonged viral shedding at univariant analysis, only older age was found to be the strongest predictor of prolonged viral shedding after stepwise multiple regression analysis. $^{32}$

Our study did not find any association between duration of viral shedding and age or presence of comorbidities. This could be attributed to our cohort's nature as it consisted of young, healthy patients with a median (IQR) age of 30.0 (20-47), with a fewer number of patients had hypertension, diabetes mellitus, or other comorbidities. No gender effect on the viral shedding was seen in our cohort population, which is concordant with other studies' findings, ${ }^{7,29,36}$ including a study from the Republic of Korea by Noh et al in which 199 patients with COVID19 with a mean age of 38.0 years, were found to have a mean duration of viral shedding of 24.5 days and was longer in symptomatic patients compared to asymptomatic ones (25.2 days versus 22.6 days, $p<0.01){ }^{41}$

With the emergence of data indicating that although clinically recovered COVID-19 patients may continue to shed detectable-RNA in upper respiratory specimens for up to 3 months after illness onset, they are unlikely infectious to others; CDC released a new "symptoms-based" strategy for the completion and ending of quarantine or isolation for persons with COVID-19 in place of previously adopted "test-based" strategy. ${ }^{42-44}$ CDC suggests that COVID-19 cases with mild-to-moderate illness can discontinue their isolation ten days from onset of symptoms, ten days after the date of their first positive RT-PCR test in asymptomatic patients, and 20 days if severely immunocompromised or suffered a severe illness; with at least 24 hours since last fever has passed in both groups. ${ }^{43}$ Our study is one of few in the literature to indicate prolonged viral shedding after symptom resolution. Therefore, enforcing further social distancing and facemask-wearing should be encouraged even after the assumed symptomatic period has ended.
Most patients from the outbreaks described in this study had mild or no symptoms, which might be a limitation of this study. However, including closely monitored asymptomatic patients with serial RT-PCR tests throughout the disease course allowed a better understanding of the clinical pattern of COVID-19 infection. The study measured the clinical and viral cure durations based on the first positive and suspected exposure times.

This study has a few other limitations; first, the study described the outbreaks in Northern Jordan, with a relatively small sample that mainly consisted of relatively young and healthy subjects, which limited the generalization of our findings outside the regional interest. Second, some COVID-19 cases had intermittent inconclusive or negative test results during serial RT-PCR testing; therefore, the test needed to be repeated the next day, which may have resulted in a longer hospital stay. Third, we did not detect the presence of viral RNA in patients' excretions other than respiratory secretions, such as urine and fecal specimens. Previous studies indicated that viral load in the stool might be more significant and continue for a longer time than that in the respiratory secretions, and the existence of viral RNA in blood could be a strong indicator of clinical severity. ${ }^{45-47}$ It should be noted that this study did not provide evidence for the infectiousness of the patients who tested positive.

\section{Conclusion}

Two major outbreaks of COVID-19 in the Northern region of Jordan took up to four weeks from the date of each outbreak's peak to finally clear with a median viral shedding duration of 13 days. Having symptoms or/and the presence of abnormal radiological findings were associated with delayed viral clearance. The incubation period may prolong beyond 14 days, and symptomatic COVID-19 patients may still have respiratory viral shedding for up to 20 days after clinical cure. Although infectivity duration is yet to be determined, having such prolonged periods of viral shedding and incubation reveals the importance of supporting and following social distancing and applying simple protective procedures such as facemask-wearing and regular hand hygiene long after the resolution of symptoms.

\section{Data Sharing Statement}

The datasets generated and analyzed during the current study are available with the corresponding author: AbdelHameed Al-Mistarehi; P.O.Box: (630001) Irbid (22110) Jordan; Email, awalmistarehi18@med.just.edu.jo. 


\section{Compliance with Ethical Standards}

All procedures performed in this study involving human participants were reviewed and ethically approved by the Institutional Review Board (IRB) and the research and ethics committee at Jordan University of Science and Technology. This study was conducted following the 1975 Helsinki declaration, as revised in 2008 and its later amendments or comparable ethical standards.

\section{Informed Consent}

Written informed consent was obtained from all individual participants included in the study.

\section{Acknowledgment}

We gratefully acknowledge all healthcare workers involved in the diagnosis and treatment of COVID-19 patients in KAUH. We thank Ali Bani Issa, Enas Bataineh, Heba Al Zamel, and Reem Qdaisat for their assistance on data collection for patients with 2019nCoV infection. We also thank Rima Al-Khatib for her assistance in reviewing and editing the manuscript.

\section{Funding}

This research did not receive any grant from funding agencies in the public, commercial, or not-for-profit sectors.

\section{Disclosure}

The authors declare that they have no competing interests in this work.

\section{References}

1. Samrah SM, Al-Mistarehi AW, Ibnian AM, et al. COVID-19 outbreak in Jordan: epidemiological features, clinical characteristics, and laboratory findings. Ann Med Surg (Lond). 2020;57:103-108. doi:10.1016/j.amsu.2020.07.020

2. Khan M, Khan H, Khan S, Nawaz M. Epidemiological and clinical characteristics of coronavirus disease (COVID-19) cases at a screening clinic during the early outbreak period: a single-centre study. $J$ Med Microbiol. 2020;69(8):1114-1123. doi:10.1099/jmm.0.001231

3. Fu L, Wang B, Yuan T, et al. Clinical characteristics of coronavirus disease 2019 (COVID-19) in China: a systematic review and meta-analysis. $J \quad$ Infect. $2020 ; 80(6): 656-665 . \quad$ doi:10.1016/j. jinf.2020.03.041

4. Samrah SM, Al-Mistarehi AH, Aleshawi AJ, et al. Depression and coping among COVID-19-infected individuals after 10 days of mandatory in-hospital quarantine, Irbid, Jordan. Psychol Res Behav Manag. 2020;13:823-830. doi:10.2147/PRBM.S267459

5. Khassawneh AH, Alrabadi N, Al-Mistarehi AH, Obeidat N, Kheirallah KA. The role of non-state actors in combating COVID-19 spread in Northern Jordan. Ann Med Surg (Lond). 2020;60:484-486. doi:10.1016/j.amsu.2020.11.005
6. Kheirallah KA, Alsinglawi B, Alzoubi A, et al. The effect of strict state measures on the epidemiologic curve of COVID-19 infection in the context of a developing country: a simulation from Jordan. Int J Environ Res Public Health. 2020;17(18):6530. doi:10.3390/ ijerph17186530

7. Hu X, Xing Y, Jia J, et al. Factors associated with negative conversion of viral RNA in patients hospitalized with COVID-19. Sci Total Environ. 2020;728:138812. doi:10.1016/j.scitotenv.2020.138812

8. Nalla AK, Casto AM, Huang MW, et al. Comparative performance of SARS-CoV-2 detection assays using seven different primer-probe sets and one assay kit. J Clin Microbiol. 2020;13(6). doi:10.2147/ PRBM.S267459

9. CDC. Test-based strategy for discontinuing transmission-based precautions. centers for disease control and prevention (CDC); 2020. Available from: https://www.cdc.gov/coronavirus/2019-ncov/hcp/dis position-hospitalized-patients.html. Accessed February 24, 2021.

10. Lauer SA, Grantz KH, Bi Q, et al. The incubation period of Coronavirus Disease 2019 (COVID-19) from publicly reported confirmed cases: estimation and application. Ann Intern Med. 2020;172 (9):577-582. doi:10.7326/M20-0504

11. Yusef D, Hayajneh W, Awad S, et al. Large outbreak of coronavirus disease among wedding attendees, Jordan. Emerg Infect Dis. 2020;26 (9):2165-2167. doi:10.3201/eid2609.201469

12. Buitrago-Garcia D, Egli-Gany D, Counotte MJ, et al. Occurrence and transmission potential of asymptomatic and presymptomatic SARS-CoV-2 infections: a living systematic review and meta-analysis. PLoS Med. 2020;17(9):e1003346. doi:10.1371/journal.pmed.1003346

13. Ferretti L, Wymant C, Kendall M, et al. Quantifying SARS-CoV-2 transmission suggests epidemic control with digital contact tracing. Science. 2020;368(6491):eabb6936. doi:10.1126/science.abb6936

14. Zou L, Ruan F, Huang M, et al. SARS-CoV-2 viral load in upper respiratory specimens of infected patients. $N$ Engl J Med. 2020;382 (12):1177-1179. doi:10.1056/NEJMc2001737

15. Huang L, Zhang X, Zhang X, et al. Rapid asymptomatic transmission of COVID-19 during the incubation period demonstrating strong infectivity in a cluster of youngsters aged 16-23 years outside Wuhan and characteristics of young patients with COVID-19: a prospective contact-tracing study. J Infect. 2020;80(6):e1-e13. doi:10.1016/j.jinf.2020.03.006

16. Xie M, Chen Q. Insight into 2019 novel coronavirus - An updated interim review and lessons from SARS-CoV and MERS-CoV. Int J Infect Dis. 2020;94:119-124. doi:10.1016/j.ijid.2020.03.071

17. Li Q, Guan X, Wu P, et al. Early transmission dynamics in Wuhan, China, of novel coronavirus-infected pneumonia. $N$ Engl $J$ Med. 2020;382(13):1199-1207. doi:10.1056/NEJMoa2001316

18. Backer JA, Klinkenberg D, Wallinga J. Incubation period of 2019 novel coronavirus (2019-nCoV) infections among travellers from Wuhan, China, 20-28 January 2020. Euro Surveill. 2020;25(5). doi:10.2807/1560-7917.ES.2020.25.5.2000062

19. Zhang J, Litvinova M, Wang W, et al. Evolving epidemiology and transmission dynamics of coronavirus disease 2019 outside Hubei province, China: a descriptive and modelling study. Lancet Infect Dis. 2020;20(7):793-802. doi:10.1016/S1473-3099(20)30230-9

20. Nie X, Fan L, Mu G, et al. Epidemiological characteristics and incubation period of 7015 confirmed cases with coronavirus disease 2019 outside Hubei Province in China. J Infect Dis. 2020;222 (1):26-33. doi:10.1093/infdis/jiaa211

21. Bai Y, Yao L, Wei T, et al. Presumed asymptomatic carrier transmission of COVID-19. JAMA. 2020;323(14):1406-1407. doi:10.1001/ jama.2020.2565

22. Zhou F, Yu T, Du R, et al. Clinical course and risk factors for mortality of adult inpatients with COVID-19 in Wuhan, China: a retrospective cohort study. Lancet. 2020;395(10229):1054-1062. doi:10.1016/S0140-6736(20)30566-3 
23. Velavan TP, Meyer CG. Mild versus severe COVID-19: laboratory markers. Int $J$ Infect Dis. 2020;95:304-307. doi:10.1016/j. ijid.2020.04.061

24. Xie J, Covassin N, Fan Z, et al. Association between hypoxemia and mortality in patients with COVID-19. Mayo Clin Proc. 2020;95 (6):1138-1147. doi:10.1016/j.mayocp.2020.04.006

25. Hussain A, Vasas P, El-Hasani S. Letter to the Editor: obesity as a risk factor for greater severity of COVID-19 in patients with metabolic associated fatty liver disease. Metabolism. 2020;108:154256. doi:10.1016/j.metabol.2020.154256

26. Zhang J, Wang X, Jia X, et al. Risk factors for disease severity, unimprovement, and mortality in COVID-19 patients in Wuhan, China. Clin Microbiol Infect. 2020;26(6):767-772. doi:10.1016/j. cmi.2020.04.012

27. Young BE, Ong SWX, Kalimuddin S, et al. Epidemiologic features and clinical course of patients infected with SARS-CoV-2 in Singapore. JAMA. 2020;323(15):1488-1494. doi:10.1001/ jama.2020.3204

28. Lee S, Kim T, Lee E, et al. Clinical course and molecular viral shedding among asymptomatic and symptomatic patients with SARS-CoV-2 infection in a community treatment center in the Republic of Korea. JAMA Intern Med. 2020;180(11):1447. doi:10.1001/jamainternmed.2020.3862

29. Uhm JS, Ahn JY, Hyun J, et al. Patterns of viral clearance in the natural course of asymptomatic COVID-19: comparison with symptomatic non-severe COVID-19. Int J Infect Dis. 2020;99:279-285. doi:10.1016/j.ijid.2020.07.070

30. Liu Y, Yan LM, Wan L, et al. Viral dynamics in mild and severe cases of COVID-19. Lancet Infect Dis. 2020;20(6):656-657. doi:10.1016/ S1473-3099(20)30232-2

31. Bongiovanni M, Marra AM, De Lauretis A, et al. Natural history of SARS-CoV-2 infection in healthcare workers in Northern Italy. J Hosp Infect. 2020;106(4):709-712. doi:10.1016/j.jhin.2020.08.027

32. Bongiovanni M, Bini F, Giuliani G, Gianturco L. Insight into the reason of prolonged viral RNA shedding in patients with COVID-19 infection. J Infect. 2021. doi:10.1016/j.jinf.2020.12.030

33. Chang D, Mo G, Yuan X, et al. Time kinetics of viral clearance and resolution of symptoms in novel coronavirus infection. Am J Respir Crit Care Med. 2020;201(9):1150-1152. doi:10.1164/rccm.2020030524LE

34. Xiao AT, Tong YX, Zhang S. Profile of RT-PCR for SARS-CoV-2: a preliminary study from 56 COVID-19 patients. Clin Infect Dis. 2020;71(16):2249-2251. doi:10.1093/cid/ciaa460

35. Bongiovanni M, Vignati M, Giuliani G, et al. The dilemma of COVID-19 recurrence after clinical recovery. $J$ Infect. 2020;81 (6):979-997. doi:10.1016/j.jinf.2020.08.019
36. Liao T, Yin Z, Xu J, et al. The correlation between clinical features and viral RNA shedding in outpatients with COVID-19. Open Forum Infect Dis. 2020;7(8):ofaa331. doi:10.1093/ofid/ofaa331

37. Shi D, Wu W, Wang Q, et al. Clinical characteristics and factors associated with long-term viral excretion in patients with severe acute respiratory syndrome coronavirus 2 infection: a single-center 28-day study. J Infect Dis. 2020;26(9):910-918. doi:10.3201/eid2609.201469

38. Xu K, Chen Y, Yuan J, et al. Factors associated with prolonged viral RNA shedding in patients with coronavirus disease 2019 (COVID-19). Clin Infect Dis. 2020;71(15):799-806. doi:10.1093/ $\mathrm{cid} / \mathrm{ciaa} 351$

39. Chen X, Zhu B, Hong W, et al. Associations of clinical characteristics and treatment regimens with the duration of viral RNA shedding in patients with COVID-19. Int $J$ Infect Dis. 2020;98:252-260. doi:10.1016/j.ijid.2020.06.091

40. Fang Z, Zhang Y, Hang C, Ai J, Li S, Zhang W. Comparisons of viral shedding time of SARS-CoV-2 of different samples in ICU and non-ICU patients. $J$ Infect. 2020;81(1):147-178. doi:10.1016/j. jinf.2020.03.013

41. Noh JY, Yoon JG, Seong H, et al. Asymptomatic infection and atypical manifestations of COVID-19: comparison of viral shedding duration. $J \quad$ Infect. 2020;81(5):816-846. doi:10.1016/j. jinf.2020.05.035

42. Xiao F, Sun J, Xu Y, et al. Infectious SARS-CoV-2 in feces of patient with severe COVID-19. Emerg Infect Dis. 2020;26(8):1920-1922. doi:10.3201/eid2608.200681

43. CDC. Duration of isolation and precautions for adults with COVID-19; 2020. Available from: https://www.cdc.gov/coronavirus/ 2019-ncov/hcp/duration-isolation.html?CDC_AA_refVal=https\%3A $\% 2 \mathrm{~F} \% 2 \mathrm{Fwww}$.cdc.gov $\% 2 \mathrm{Fcoronavirus} \% 2 \mathrm{~F} 2019$-ncov $\%$ 2Fcommunity $\% 2$ Fstrategy-discontinue-isolation.html. Accessed February 24, 2021.

44. Korea. Korea Centers for Disease Control and Prevention. Findings from investigation and analysis of re-positive cases; 2020. Available from: http://www.kdca.go.kr/board/board.es? mid= a30402000000\&bid $=0030 \&$ act $=$ view \&list $\_$no $=367267 \&$ nPage $=$ 1external\%20icon. Accessed February 24, 2021.

45. Xu Y, Li X, Zhu B, et al. Characteristics of pediatric SARS-CoV-2 infection and potential evidence for persistent fecal viral shedding. Nat Med. 2020;26(4):502-505. doi:10.1038/s41591-020-0817-4

46. Zhang N, Gong Y, Meng F, et al. Comparative study on virus shedding patterns in nasopharyngeal and fecal specimens of COVID-19 patients. Sci China Life Sci. 2020. doi:10.1007/s11427-020-1783-9

47. Chen W, Lan Y, Yuan X, et al. Detectable 2019-nCoV viral RNA in blood is a strong indicator for the further clinical severity. Emerg Microbes Infect. 2020;9(1):469-473. doi:10.1080/22221751.2020.1732837
Journal of Multidisciplinary Healthcare

\section{Publish your work in this journal}

The Journal of Multidisciplinary Healthcare is an international, peerreviewed open-access journal that aims to represent and publish research in healthcare areas delivered by practitioners of different disciplines. This includes studies and reviews conducted by multidisciplinary teams as well as research which evaluates the results or conduct of such teams or healthcare processes in general. The journal covers a very wide range of areas and welcomes submissions from practitioners at all levels, from all over the world. The manuscript management system is completely online and includes a very quick and fair peer-review system. Visit http://www.dovepress.com/testimonials. php to read real quotes from published authors. 